\title{
FAKTOR DETERMINAN SOSIAL MEMPENGARUHI MANAJEMEN LAKTASI PADA IBU HAMIL DIWILAYAH KERJA PUSKESMAS KALUMATA KECAMATAN TERNATE SELATAN KOTA TERNATE TAHUN 2013
}

\author{
Sulima Hamadun Gay ${ }^{*)}$
}

\begin{abstract}
Lactation management for pregnant women is based on the consequences of the process of growth and development of the baby in the womb until the time of birth and during early life gold. This study aims to determine the relationship determinant with maternal lactation management working area Kalumata District Health Center South Ternate Ternate in North Maluku. In 2013.This type of research is a quantitative study with a cross-sectional study design. Large sample of 180 pregnant women first and second trimester. Data analysis was done by Chi Scuare test and correction by using logistic regression. The results showed that there is a relationship between knowledge ( $\mathrm{p}$ $=0.000)$, compliance $(p=0.000)$, husband's support $(p=0.000)$, health care $(p=0.000)$, the ability of officers $(p=$ $0.001)$, and the local culture $\mathrm{p}=0.002)$ while there was no association of economic status $(\mathrm{p}=0148)$ on the implementation of management of lactation in pregnant women. From this study it can be concluded that the bulk of the determinant factors related to the implementation of the management of lactation in pregnant women, therefore, required the participation or cooperation of all parties in order to increase coverage breastfeeding infants.
\end{abstract}

Keywords : determinant factors, pregnant women, lactation management.

\section{PENDAHULUAN}

\section{Latar Belakang}

Manajemen laktasi adalah tata laksana yang diperlukan untuk menunjang keberhasilan menyusui. Dalam pelaksanaannya terutama dimulai pada masa kehamilan segera setelah persalinan dan pada masa menyusui selanjutnya (Direktorat Gizi Masyarakat, 2005).

Di Indonesia kematian bayi berdasarkan hasil SDKI 2007 Angka Kematian Bayi (AKB) adalah 34 per 1000 kelahiran hidup dan Angka Kematian Balita (AKABA) adalah 44 per 1000 kelahiran hidup dan penyebab dari kematian ini bervariasi namun tertinggi adalah akibat defesiensi zat gizi yaitu sebesar 59,3\%.

Menurut UNICEF tahun 2009, bahwa angka cakupan praktek inisiasi menyusui dini (IMD) dari tahun 2003 sampai 2008 sebesar $40 \%$ dan cakupan ASI eksklusif hanya sebesar $40 \%$ sementara menurut Survei demografi kesehatan Indonesia (SDKI) tahun 2007 bahwa bayi usia dibawah empat bulan yang diberi ASI secara eksklusif sebesar $41 \%$ dan bayi usia 6 bulan lebih rendah yaitu sebesar 32\%. Indonesia tahun 2008 dalam Profil Kesehatan Indonesia 2007, cakupan Pemberian ASI eksklusifPropinsi Maluku Utaramasih sangat rendah yaitu $(25,22 \%)$ di daerah perkotaan dan $(19,35 \%)$ di daerah pedesaan,angka tersebut masih jauh dari target nasional sebesar $80 \%$. Sementara Kota ternate cakupan pemberian ASI eksklusif saat ini baru mencapai $51 \%$ dan untuk pencapaian ASI eksklusif untuk wilayah kerja Puskesmas Kalumata sendiri mencapai $58 \%$.

\section{Rumusan Masalah}

a. Bagaimana pengaruh hubungan pengetahuan ibu hamil terhadap pelaksanaan manajemen laktasi

b. Bagaimana pengaruh kepatuhan ibu hamilterhadap pelaksanaan manajemen laktasi.

c. Bagaimana pengaruh dukungan suami terhadap pelaksanaan manajemen Laktasi

d. Bagaimana pengaruh sosial ekonomi terhadap pelaksanaan manajemen laktasi

e. Bagaimana pengaruh sosial budaya terhadap pelaksanaan manajemen laktasi.

\section{Tujuan Penelitian}

1. Tujuan Umum

Untuk mengetahui dan menganalisis bagaimana faktor determinan sosial yang mempengaruhi manajemen laktasi pada ibu hamil di wilayah kerja puskesmas Kalumata kecamatan Kota Ternate Selatan Kota Ternate

2. Tujuan khusus
a. Untuk
pengetahuan
mengetahui
hubungan pelaknaan manajemen laktasi.
b. Untuk mengetahui hubungan kepatuhan ibu terhadap pelaksanaan manajemen laktasi.


c. Untuk mengetahui hubungan dukungan suami terhadap pelaksanaan manajemen Laktasi.

d. Untuk mengetahui pengaruh sosial ekonomi terhadap pelaksanaan manajemen laktasi.

e. Untuk mengetahui hubungan sosial budaya terhadap pelaksanaan manajemen laktasi.

\section{Manfaat Penelitian}

Penilitian ini diharapkan dapat memperoleh manfaat antara lain :

1. Manfaat ilmiah yaitu diharapkan hasil penelitian ini dapat menambah dan memperkaya wawasan dan ilmu pengetahuan.

2. Manfaat praktis yaitu meningkatkan promosi mengenai konseling laktasi pada ibu hamil dan ibu menyusui.

3. Manfaat bagi peneliti yaitu sebagai pembelajaran didalam menambah pengalaman ilmiah dan berpikir kritis dalam mengkaji teori dan realitas dimasyarakat dalam upaya meningkatkan derajat kesehatan ibu dan anak.

\section{METODE PENELITIAN}

\section{Desain Penelitian}

Penelitian ini menggunakan desain " Studi potong lintang" ( Crossectional study) yang merupakan salah satu jenis rancangan penelitian yang sifatnya analitik dan termasuk dalam jenis rancangan penelitian observasional.

Variabel independen yang tergabung dalam faktor determinan manajemen laktasi adalah : ( pengetahuan, kepatuhan, fasilitas pelayanan, kemampuan petugas kesehatan, dukungan suami, sosial ekonomi dan sosial budaya.) sedangkan variabel dependennya adalah manajemen laktasi).

\section{Populasi Dan Sampel}

\section{Populasi Penelitian}

Yang menjadi populasi penelitian ini adalah seluruh ibu hamil yang berada diwilayah kerja puskesmas Kalumata Kecamatan Kota Ternate Selatan.

\section{Sampel Penelitian}

Sampel penelitian ditarik dari populasi penelitian yang disusun sebagai berikut :

a. Unit observasi, ibu hamil trimester II dan III yang berada di wilayah kerja puskesmas kalumata saat penelitian berlangsung

b. Unit analisis. Adalah pelaksanaan manajemen laktasi dan faktor determinan yang mempengaruhi ( pengetahuan ibu, kepatuhan ibu , dukungan suami, sosial ekonomi dan sosial budaya) yang melekat pada unit observasai.

c. Besar sampel. Dihitung dengan menggunakan rumus sampel untuk penelitian kesehatan dengan populasi $(\mathrm{N})$ diketahui, seperti diperkenalkan oleh Stanley Lemeshow, dkk :1997, untuk jenis penelitian observasional dengan rumus sebagai berikut:

$$
\begin{aligned}
& \mathrm{n}=\frac{\mathrm{Z}^{2} \cdot 1-\alpha / 2 \mathrm{P}(1-\mathrm{p}) \mathrm{N}}{\mathrm{d}^{2}(\mathrm{~N}-1)+\mathrm{Z}^{2} \cdot 1-\alpha / 2 \mathrm{P}(1-\mathrm{p})} \\
& \mathrm{n}=\frac{1,98(1-0,5) 667}{0,05^{2}(667-1)+1,98(1-0,5)} \\
& \mathrm{n}=\frac{1,98(1-0,5) 667}{0,0025(667-1)+1,98(1-0,5)} \\
& \mathrm{n}=\frac{660.33}{3.645}=181.16=181
\end{aligned}
$$

Keterangan :

$\mathrm{N}$ : Besar Sampel Minimal penelitian

$\mathrm{Z}^{2}$.1: Nilai distribusi normal standar diman untuk $\alpha=0.05$ nilainya $=1.96 \alpha / 2 \mathrm{P}$

$\mathrm{p} \quad$ : Presentasi Upaya penurunan prevalensi yang dilakukan dalam populasi dan bila tidak diketahui maka ditetapkan $(\%)=0.5$

$\mathrm{d}$ : Tingkat presisi yang diinginkan (ditetapkan=0.5)

$\mathrm{N} \quad$ : Jumlah populasi $=667$.

Tabel 1: Distribusi Jumlah Ibu Hamil Trimester II dan III menurut Kelurahan di wilayah kerja Puskesmas Kalumata Kecamatan Ternate Selatan 


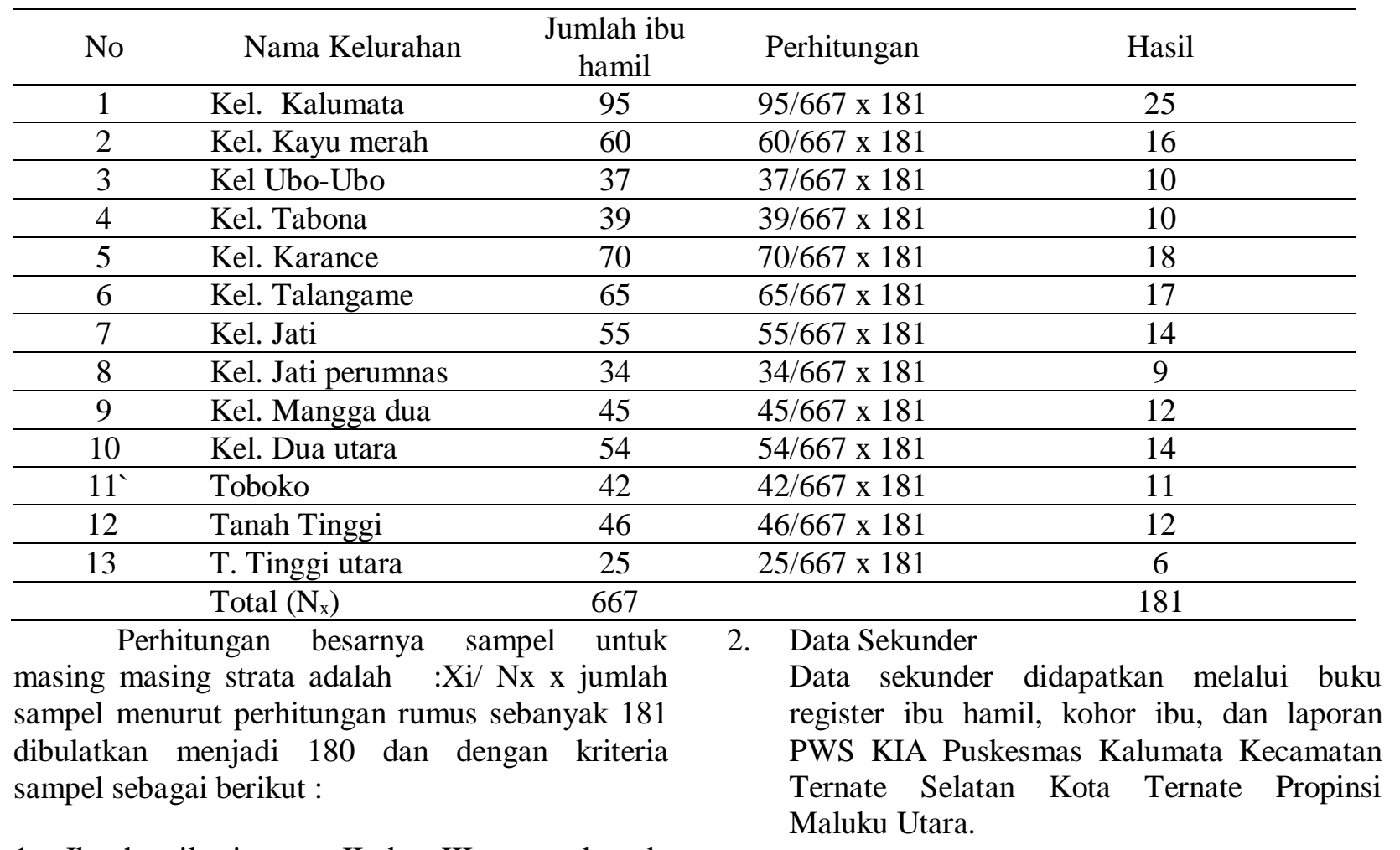

1. Ibu hamil trimester II dan III yang berada diwilayah kerja Puskesmas Kalumata kecamatan Kota Ternate Selatan.

HASIL PENELITIAN DAN PEMBAHASAN

2. Berdomisili diwilayah Kecamatan kota Ternate Selatan.

3. Bersedia menjadi anggota sampel dengan menandatangani inform consent

\section{Tehnik penarikan.}

Tehnik penarikan sampel pada penelitian ini dilakukan dengan cara berstrata (stratifield proportional random sampling) sesuai dengan kriteri sampel yng telah ditetapkan pada populasi penelitian,

\section{Lokasi Dan Waktu Penelitian}

Penelitian ini direncanakan akan dilaksanakan selama dua bulan yaitu dari bulan maret sampai dengan bulan april 2013, di Puskesmas kalumata kecamatan Kota Ternate Selatan

\section{Cara Pengumpulan Data}

Jenis data yang digunakan dalam penelitian ini adalah :

1. Data Primer

Data primer diperoleh melalui kuesioner yang diberikan langsung kepada responden.

\section{Hasil Penelitian}

1) Gambaran umum Puskesmas Kalumata Kecamatan Ternate Selatan Kota Ternate Provinsi Maluku Utara.

a. Letak Geografis.

Puskesmas Kalumata merupakan Unit Pelaksanaan Teknis Dinas (UPTD) dari Dinas Kesehatan Kota Ternate yang melaksanakan Tugas Tekhnis Operasional Pembangunan Kesehatan, yang membawahi 13 kelurahan dengan batas wilayah yaitu :

1. Sebelah Utara berbatasan dengan Kelurahan Takoma.

2. Sebelah Timur berbatasan dengan Laut Ternate.

3. Sebelah Selatan berbatasan dengan kelurahan Ngade.

4. Sebelah Barat berbatasan dengan gunung Gamalama.

b. Keadaan Topografi.

Wilayah kerja Puskesmas Kalumata memiliki luas wilayah sekitar 17,5 $\mathrm{km}^{2}$ yang terdiri dari 13 Kelurahan Ternate selatan terdiri dari daerah dataran rendah dengan ketinggian wilayah $2-6$ meter dari permukaan laut dan dataran tinggi dengan 
rata-rata ketinggian wilayah $500-699$ meter dari permukaan laut.

\section{c. Kependudukan.}

Berdasarkan registrasi penduduk akhir tahun 2011, jumlah penduduk di wilayah kerja Puskesmas Kalumata tercatat sebanyak 53.176 jiwa yang terdiri atas 23.783 laki-laki dan 29.3923 perempuan dengan pertumbuhan penduduk $2 \%$ dan jumlah rumah sebanyak 10.881 .

\section{Analisis Hasil Penelitian}

\section{a. Analisis data umum.}

Dengan analisis ini, dimaksudkan untuk menilai beberapa karakteristik umum atau data umum ibu hamil trimester II dan III, yang dianggap memberi kontribusi terhadap variabel manajemen laktasi , yang disajikan sebagai berikut:

Tabel. 2. Distribusi ibu hamil trimester II dan III, menurut kelompok umur di wiayah kerja Puskesmas kalumata Kecamatan Ternate Selatan kota Ternate, Provinsi Maluku Utara Tahun 2013

\begin{tabular}{ccc}
\hline Keompok Umur (tahun) & $\mathbf{N}$ & $\boldsymbol{\%}$ \\
\hline $20<$ & 7 & 4.8 \\
$20-35$ & 164 & 89.3 \\
$>35$ & 9 & 5.9 \\
\hline & $\mathbf{1 8 0}$ & $\mathbf{1 0 0 . 0}$ \\
\hline
\end{tabular}

Sumber : Data Primer

Tabel 2 memperlihatkan distribusi

kelompok umur yang tidak beresiko reproduksi 20 kelompok umur responden terbanyak berada pada sampai 35 tahun yaitu sebesar (89.3\%)

Tabel. 3. Distribusi ibu hamil trimester II dan III, menurut tingkat pendidikan di wilayah kerja Puskesmas Kalumata Kecamatan Ternate Selatan Kota Ternate, Provinsi Maluku Utara Tahun 2013

\begin{tabular}{lcc}
\hline Tingkat pendidikan & N & \% \\
\hline SD & 7 & 3.9 \\
SMP & 35 & 19.4 \\
SMA & 109 & 60.6 \\
Akademi/P T & 29 & 16.1 \\
\hline & $\mathbf{1 8 0}$ & $\mathbf{1 0 0 , 0}$ \\
\hline
\end{tabular}

Sumber : Data Primer

Tabel 3 menunjukkan tingkat pendidikan bervariasi dari pendidikan terendah SD sampai pendidikan Akademi atau perguruan tinggi.

Kelompok pendidikan terbesar adalah SMU $(60.6 \%)$.

Tabel 4 Distribusi ibu hamil trimester II dan III, menurut jenis pekerjaan di wilayah kerja Puskesmas Kalumata Kecamatan Ternate Selatan Kota Ternate Propinsi Maluku Utara Tahun 2013 


\begin{tabular}{ccc}
\hline PNS & 30 & 16.7 \\
Pegawai Swasta & 24 & 13.3 \\
tidak bekerja(IRT) & 126 & 70.0 \\
\hline & $\mathbf{1 8 0}$ & $\mathbf{1 0 0 . 0}$ \\
\hline
\end{tabular}

Tabel 4 menunjukkan jenis pekerjaan bervariasi dari IRT sampai dengan PNS, dengan jenis pekerjaan terbesar adalah IRT $(70 \%)$.

b. Analisis Data Khusus.

Dengan analisis ini, dimaksudkan untuk menilai beberapa karakteristik ibu hamil trimester II dan III, yakni pengetahuan, kepatuhan, dukungan suami, pelayanan kesehatan, kemampuan petugas kesehatan, status ekonomi dan budaya lokal yang disajikan sebagai berikut:

Tabel 5 Distribusi ibu hamil trimester II dan III, menurut faktor determinan di wilayah Kerja Puskesmas Kalumata Kecamatan Ternate Selatan Kota Ternate Propinsi Maluku Utara Tahun 2013

\begin{tabular}{|c|c|c|c|c|c|c|c|}
\hline \multirow[b]{3}{*}{ VARIABEL } & \multirow{3}{*}{ Kriteria obyektif } & \multicolumn{4}{|c|}{ Manajemen laktasi (perawatan payudara) } & \multirow{2}{*}{\multicolumn{2}{|c|}{ Jumlah }} \\
\hline & & \multicolumn{2}{|c|}{ Baik } & \multicolumn{2}{|c|}{ Kurang } & & \\
\hline & & $\mathrm{N}$ & $\%$ & $\mathrm{~N}$ & $\%$ & $\mathrm{n}$ & $\%$ \\
\hline \multirow{2}{*}{$\begin{array}{l}\text { pengetahuan } \\
\text { Bumil }\end{array}$} & Baik & 77 & 79.4 & 44 & 53.0 & 121 & 67.2 \\
\hline & Kurang & 20 & 20.6 & 39 & 47.0 & 59 & 32.8 \\
\hline \multirow{2}{*}{$\begin{array}{l}\text { Kepatuhan } \\
\text { Bumil }\end{array}$} & Baik & 90 & 92.8 & 55 & 66.3 & 145 & 80.6 \\
\hline & Kurang & 7 & 7.2 & 28 & 33.7 & 35 & 19.4 \\
\hline \multirow{2}{*}{$\begin{array}{l}\text { Dukungan } \\
\text { suami }\end{array}$} & Baik & 73 & 75.3 & 46 & 55.4 & 119 & 661 \\
\hline & Kurang & 24 & 24.7 & 37 & 44.6 & 61 & 33.9 \\
\hline \multirow{2}{*}{$\begin{array}{l}\text { Pelayanan } \\
\text { Kesehatan }\end{array}$} & Baik & 75 & 77.3 & 49 & 59.0 & 124 & 68.9 \\
\hline & Kurang & 22 & 22.7 & 34 & 41.0 & 56 & 31.1 \\
\hline \multirow{2}{*}{$\begin{array}{l}\text { Kemampuan } \\
\text { petugas }\end{array}$} & Baik & 69 & 711 & 47 & 566 & 116 & 644 \\
\hline & Kurang & 28 & 28.9 & 36 & 43.4 & 64 & 35.6 \\
\hline \multirow[t]{2}{*}{ Sosial ekonomi } & Baik & 67 & 69.1 & 64 & 77.1 & 131 & 72.8 \\
\hline & Kurang & 30 & 30.9 & 19 & 22.9 & 49 & 27.2 \\
\hline \multirow[t]{2}{*}{ Sosial Budaya } & Baik & 78 & 80.4 & 51 & 61.4 & 129 & 71.7 \\
\hline & Kurang & 19 & 19.6 & 32 & 36.6 & 51 & 28.3 \\
\hline & & 97 & 100.0 & 83 & 100.0 & 180 & 100.0 \\
\hline
\end{tabular}

Sumber : Data sekunder

Dari tabel 5 memperlihatkan penelitian ini memfokuskan diri pada penilaian hubungan antara determinan (Pengetahuan, Kepatuhan, Dukungan Suami, Pelayanan Kesehatan, Kemampuan Petugas, Sosil ekonomi, Sosial Budaya ), dengan pelaksanaan manajemen laktasi pada ibu hamil trimester II dan III, yang dinilai melalui persepsi ibu dengan menggunakan kuesioner.

melihat variabel independen yang berhubungan dengan variabel dependen, 97 (51.7\%) memiliki kemampuan melaksanakan manajemen laktasi yang baik dan 83 (48.3\%) kemampuan penatalaksanaan manajemen laktasi kurang yang diukur menggunakan skala Guthman.)

\section{c. Analisis tabulasi silang determinan dengan manajemen Laktasi.}

Pada tahap ini dilakukan analisis tabulasi silang antara variabel variabel yang termasuk determinan dengan variabel manajemen 
laktasi, yang disajikan dalam bentuk tabel

berikut

Tabel. 6. Hubungan pengetahuan ibu hamil dengan pelaksanaan manajemen laktasi di wilayah kerja Puskesmas kalumata kecamatan Ternate selatan Kota ternate Propinsi maluku Utara tahun 2013

\begin{tabular}{|c|c|c|c|c|c|c|c|}
\hline \multirow{3}{*}{$\begin{array}{c}\text { Pengetahuan ibu } \\
\text { hamil }\end{array}$} & \multicolumn{4}{|c|}{$\begin{array}{c}\text { Manajemen Laktasi } \\
\text { (perawatan payudara) }\end{array}$} & \multirow{2}{*}{\multicolumn{2}{|c|}{ Jumlah }} & \\
\hline & \multicolumn{2}{|c|}{ Baik } & \multicolumn{2}{|c|}{ Kurang } & & & \\
\hline & $\mathrm{n}$ & $\%$ & $\mathrm{~N}$ & $\%$ & $\mathrm{~N}$ & $\%$ & \\
\hline Baik & 77 & 63.6 & 44 & 36.4 & 121 & 100.0 & \multirow{3}{*}{$\begin{array}{l}\mathrm{p}=0.000 \\
\text { Phi }=0.280\end{array}$} \\
\hline Kurang & 20 & 33.9 & 39 & 66.1 & 59 & 100.0 & \\
\hline & 97 & 51.7 & 83 & 48.3 & 180 & 100.0 & \\
\hline
\end{tabular}

Sumber

: data primer

Tabel 6 memperlihatkan hasil analisis hubungan pengetahuan ibu hamil dengan pelaksanaa manajemen laktasi menunjukan bahwa,dari total responden (180) terdapat terdapat $121(67.2 \%)$ yang memiliki pengetahuan baik dan terdapat 59 (32.8\%) memiliki pengetahuan kurang . Dari jumlah ibu hamil yang memiliki

pengetahuan baik tidak semua mempunyai manajemen laktasi baik hanya (63.6\%) yang memiliki manajemen laktasi baik. Hasil Uji ChiSquare memperlihatkan nilai $\mathrm{p}=0,000$ lebih kecil dari nilai $\alpha=0.05$. sehingga disimpulkan terdapat hubungan pengetahuan ibu hamil dengan manajemen laktasi.

Tabel. 7. Hubungan Kepatuhan ibu hamil dengan pelaksanaan manajemen laktasi di wilayah kerja Puskesmas Kalumata Kecamatan Ternate Selatan Kota Ternate Propinsi Maluku UtaraTahun 2013

\begin{tabular}{|c|c|c|c|c|c|c|c|}
\hline \multirow{3}{*}{$\begin{array}{l}\text { Kepatuhan ibu } \\
\text { hamil }\end{array}$} & \multicolumn{4}{|c|}{$\begin{array}{l}\text { Manajemen Laktasi } \\
\text { (perawatan payudara) }\end{array}$} & \multirow{2}{*}{\multicolumn{2}{|c|}{ Jumlah }} & \\
\hline & \multicolumn{2}{|c|}{ Baik } & \multicolumn{2}{|c|}{ Kurang } & & & \\
\hline & $\mathrm{n}$ & $\%$ & $\mathrm{~N}$ & $\%$ & $\mathrm{~N}$ & $\%$ & \\
\hline Baik & 90 & 62.1 & 55 & 37.9 & 145 & 100,0 & \multirow{3}{*}{$\begin{array}{l}\mathrm{p}=0.000 \\
\text { Phi }=0.334\end{array}$} \\
\hline \multirow[t]{2}{*}{ Kurang } & 7 & 20.0 & 28 & 80.0 & 35 & 100.0 & \\
\hline & 97 & 517 & 83 & 483 & 180 & 1000 & \\
\hline
\end{tabular}

Sumber : data primer

Tabel 7 memperlihatkan hasil analisis hubungan kepatuhan ibu hamil dengan pelaksanaan manajemen laktasi menunjukan bahwa,dari total responden (180) terdapat 145 $(80.6 \%)$ yang memiliki kepatuhan baik dan 35 yang memiliki kepatuhan kurang(19.4\%). Dari jumlah ibu hamil yang memiliki kepatuhan baik

hanya terdapat $(62.1 \%)$ yang memiliki manajemen laktasi baik. Hasil Uji Chi-Square memperlihatkan nilai $\mathrm{p}=0,000$ lebih kecil dari nilai $\alpha=0.05$. sehingga disimpulkan terdapat hubungan kepatuhan ibu hamil dengan manajemen laktasi .

Tabel. 8. Hubungan dukungan suami dengan pelaksanaan manajemen laktasi di wilayah kerja Puskesmas Kalumata Kecamatan Ternate Selatan Kota Ternate Propinsi Maluku Utara Tahun 2013.

\begin{tabular}{|c|c|c|c|c|c|c|}
\hline \multirow{3}{*}{ Dukungan suami } & \multicolumn{4}{|c|}{$\begin{array}{l}\text { Manajemen Laktasi } \\
\text { (perawatan payudara) }\end{array}$} & \multirow{2}{*}{\multicolumn{2}{|c|}{ Jumlah }} \\
\hline & \multicolumn{2}{|c|}{ Baik } & \multicolumn{2}{|c|}{ Kurang } & & \\
\hline & $\mathrm{n}$ & $\%$ & $\mathrm{~N}$ & $\%$ & $\mathrm{n}$ & $\%$ \\
\hline Baik & 73 & 61.3 & 46 & 38.7 & 119 & 100,0 \\
\hline
\end{tabular}




\begin{tabular}{cccccccc}
\hline Kurang & 24 & 39.3 & 37 & 60.7 & 61 & 100,0 & $\mathrm{p}=0.005$ \\
\cline { 1 - 6 } & 97 & 51.7 & 83 & 48.3 & 180 & 100,0 & Phi $=0.209$ \\
\hline
\end{tabular}

Sumber : data primer

Tabel 8 memperlihatkan hasil analisis hubungan dukungan suami ibu hamil dengan pelaksanaan manajemen laktasi menunjukan bahwa,dari total responden (180) terdapat 119 $(66.1 \%)$ yang mendapat dukungan suami dan yang kurang mendapat dukungan suami adalah sebanyak 61 (33.9\%). Dari jumlah ibu hamil yang

mendapat dukungan suami hanya terdapat (61.3\%) yang memiliki manajemen laktasi baik. Hasil Uji Chi-Square memperlihatkan nilai $\mathrm{p}=$ 0,005 lebih kecil dari nilai $\alpha=0.05$. sehingga disimpulkan terdapat hubungan kepatuhan ibu hamil dengan manajemen laktasi .

Tabel. 9. Hubungngan pelayanan kesehatan pada ibu hamil dengan pelaksanaan manajemen laktasi di wilayah kerja Puskesmas Kalumata Kecamatan Ternate Selatan Kota Ternate Propinsi Maluku Utara Tahun 2013

\begin{tabular}{|c|c|c|c|c|c|c|c|}
\hline \multirow{3}{*}{$\begin{array}{l}\text { Pelayanan } \\
\text { Kesehatan }\end{array}$} & \multicolumn{4}{|c|}{$\begin{array}{l}\text { Manajemen Laktasi } \\
\text { (perawatan payudara) }\end{array}$} & \multirow{2}{*}{\multicolumn{2}{|c|}{ Jumlah }} & \\
\hline & \multicolumn{2}{|c|}{ Baik } & \multicolumn{2}{|c|}{ Kurang } & & & \\
\hline & $\mathrm{n}$ & $\%$ & $\mathrm{~N}$ & $\%$ & $\mathrm{n}$ & $\%$ & \\
\hline Baik & 75 & 60.5 & 49 & 39.5 & 124 & 100,0 & \\
\hline \multirow[t]{2}{*}{ Kurang } & 22 & 39.3 & 34 & 60.7 & 56 & 100,0 & $\mathrm{p}=0.008$ \\
\hline & 97 & 51.7 & 83 & 48.3 & 180 & 100,0 & Phi $=0.197$ \\
\hline
\end{tabular}

Sumber : data primer

Tabel 9 memperlihatkan hasil analisis hubungan pelayanan kesehatan dengan pelaksanaan manajemen laktasi oleh ibu hamil menunjukan bahwa,dari total responden (180) terdapat $124(68.9 \%)$ yang mendapat pelayanan yang sesuai standar dan yang kurang mendapat pelayanan sesuai standar $56(31.1 \%)$. Dari jumlah

ibu hamil yang mendapat pelayanan sesuai standar hanya terdapat ( $60.5 \%)$ yang memiliki manajemen laktasi baik. Hasil Uji Chi-Square memperlihatkan nilai $\mathrm{p}=0,008$ lebih kecil dari nilai $\alpha=0.05$. sehingga disimpulkan terdapat hubungan pelayanan kesehatan yang sesuai standar dengan pelaksanaan manajemen laktasi.

Tabel.10 Hubungan kemampuan petugas kesehatan dengan pelaksanaan manajemen laktasi di wilayah kerja Puskesmas Kalumata Kecamatan Ternate Selatan Kota Ternate Propinsi Maluku Utara Tahun 2013

\begin{tabular}{|c|c|c|c|c|c|c|c|}
\hline \multirow{3}{*}{$\begin{array}{c}\text { Kemampuan } \\
\text { petugas kesehatan }\end{array}$} & \multicolumn{4}{|c|}{$\begin{array}{c}\text { Manajemen Laktasi } \\
\text { (perawatan payudara) }\end{array}$} & \multirow{2}{*}{\multicolumn{2}{|c|}{ Jumlah }} & \\
\hline & \multicolumn{2}{|c|}{ Baik } & \multicolumn{2}{|c|}{ Kurang } & & & \\
\hline & $\mathrm{n}$ & $\%$ & $\mathrm{~N}$ & $\%$ & $\mathrm{~N}$ & $\%$ & \\
\hline Baik & 69 & 59.5 & 47 & 40.5 & 116 & 100,0 & \\
\hline \multirow[t]{2}{*}{ Kurang } & 28 & 43.8 & 36 & 56.2 & 64 & 100,0 & $\mathrm{p}=0.043$ \\
\hline & 97 & 51.7 & 83 & 48.3 & 180 & 100,0 & $\mathrm{Phi}=0.151$ \\
\hline
\end{tabular}

Sumber : data primer

Tabel 10 memperlihatkan hasil analisis hubungan kemampuan petugas kesehatan dengan pelaksanaan manajemen laktasi oleh ibu hamil menunjukan bahwa,dari total responden (180) terdapat $116(64.4 \%)$ yang menyatakan kemampuan petugas baik dan yang menyatakan kemampuan petugas kurang 64 (35.6\%). Dari jumlah ibu yang menyatakan kemampuan petugas

kesehatan dalam pelayanan ANC baik hanya terdapat (59.5\%) yang memiliki manajemen laktasi baik. Hasil Uji Chi-Square memperlihatkan nilai $\mathrm{p}=0,043$ lebih kecil dari nilai $\alpha=0.05$. sehingga disimpulkan terdapat hubungan kemampuan petugas kesehatan dengan pelaksanaan manajemen laktasi.

Tabel. 11. Hubungngan sosial ekonomi ibu hamil dengan pelaksanaan manajemen laktasi di wilayah Kerja Puskesmas Kalumata Kecamatan Ternate Selatan Kota Ternate Propinsi Maluku Utara Tahun 2013 


\begin{tabular}{|c|c|c|c|c|c|c|c|}
\hline \multirow[t]{3}{*}{ Sosial Ekonomi } & \multicolumn{4}{|c|}{$\begin{array}{c}\text { Manajemen Laktasi } \\
\text { (perawatan payudara) }\end{array}$} & \multirow{2}{*}{\multicolumn{2}{|c|}{ Jumlah }} & \\
\hline & \multicolumn{2}{|c|}{ Baik } & \multicolumn{2}{|c|}{ Kurang } & & & \\
\hline & $\mathrm{n}$ & $\%$ & $\mathrm{~N}$ & $\%$ & $\mathrm{n}$ & $\%$ & \\
\hline Baik & 67 & 51.1 & 64 & 48.9 & 131 & 100,0 & \\
\hline \multirow[t]{2}{*}{ Kurang } & 30 & 61.2 & 19 & 38.8 & 49 & 100,0 & $\mathrm{p}=0.227$ \\
\hline & 97 & 51.7 & 83 & 48.3 & 180 & 100,0 & $\mathrm{Phi}=0.090$ \\
\hline
\end{tabular}

Sumber : data primer

Tabel 11 memperlihatkan hasil analisis hubungan kemampuan sosial ekonomi dengan pelaksanaan manajemen laktasi oleh ibu hamil menunjukan bahwa,dari total responden (180) terdapat $131(72.8 \%)$ yang memiliki kemampuan sosial ekonomi baik dan terdapat 49 ( 27.2\%)yang memiliki kemampuan sosial ekonomi kurang. Dari jumlah ibu hamil yang memliki sosial ekonomi

baik hanya terdapat (51.1\%) yang memliki manajemen laktasi baik. Hasil Uji Chi-Square memperlihatkan nilai $\mathrm{p}=0,227$ lebih besar dari nilai $\alpha=0.05$. sehingga disimpulkan tidak terdapat hubungan kemampuan sosial ekonomi dengan pelaksanaan manajemen laktasi

Tabel. 12. Hubungngan pelaksanaan manajemen laktasi dengan sosial budaya di wilayah kerja Puskesmas Kalumata Kecamatan Ternate Selatan Kota Ternate Propinsi Maluku Utara Tahun 2013

\begin{tabular}{|c|c|c|c|c|c|c|c|}
\hline \multirow{3}{*}{ Sosial Budaya } & \multicolumn{4}{|c|}{$\begin{array}{l}\text { Manajemen Laktasi } \\
\text { (perawatan payudara) }\end{array}$} & \multirow{2}{*}{\multicolumn{2}{|c|}{ Jumlah }} & \\
\hline & \multicolumn{2}{|c|}{ Baik } & \multicolumn{2}{|c|}{ Kurang } & & & \\
\hline & $\mathrm{n}$ & $\%$ & $\mathrm{~N}$ & $\%$ & $\mathrm{~N}$ & $\%$ & \\
\hline Baik & 78 & 60.5 & 51 & 39.5 & 129 & 100,0 & \\
\hline \multirow[t]{2}{*}{ Kurang } & 19 & 37.3 & 32 & 62.7 & 51 & 100,0 & $\mathrm{p}=0.005$ \\
\hline & 97 & 517 & 83 & 483 & 180 & 1000 & $\mathrm{Phi}=0210$ \\
\hline
\end{tabular}

Sumber : data primer

Tabel 11 memperlihatkan hasil analisis hubungan sosial budaya dengan pelaksanaan manajemen laktasi oleh ibu hamil menunjukan bahwa,dari total responden (180) terdapat 129 $(71.7 \%)$ sosial budaya mendukung pelaksanaan manajemen laktasi dan terdapat 51 ( $28.3 \%)$ memiliki budaya yang kurang mendukung

pelaksanaan manajemen laktasi. Dari jumlah ibu hamil yang sosial budayanya baik hanya terdapat $(60.5 \%)$ yang mempunyai manajemen laktasi baik. Hasil Uji Chi-Square memperlihatkan nilai $\mathrm{p}=$ 0,005 lebih kecil dari nilai $\alpha=0.05$. sehingga disimpulkan terdapat hubungan sosial budaya dengan pelaksanaan manajemen laktasi .

Tabel. 14. Resume hasil uji chi-sqare hubungan variabel independen dengan Pelaksanaan manajemen laktasi di wilayah kerja Puskesmas Kalumata Kecamatan Ternate Selatan Kota Ternate Propinsi Maluku Utara Tahun 2013

\begin{tabular}{lccc}
\hline \multirow{2}{*}{ Variabel } & \multicolumn{3}{c}{ Hasil Uji } \\
\cline { 2 - 4 } & Chi-Square & P & Phi \\
\hline Pengetahuan bumil & 14.115 & $<0.05$ & 0.280 \\
\hline Kepatuhan bumil & 20.081 & $<0.05$ & 0.334 \\
\hline
\end{tabular}




\begin{tabular}{llll}
\hline Dukungan suami & 7.855 & $<0.05$ & 0.209 \\
\hline Pelayanan Kesehatan & 6.976 & $<0.05$ & 0.197 \\
\hline Kemampuan Petugas & 4.108 & $<0.05$ & 0.151 \\
\hline Sosial Ekonomi & 1.458 & $>0.05$ & 0.090 \\
\hline Sosial Budaya & 7.924 & $<0.05$ & 0.210 \\
\hline
\end{tabular}

Sumber : data primer

Tabel 14 menunjukkan dari tujuh variabel independen yang diobservasi terlihat variabel pengetahuan dan kepatuhan yang memberi hubungan terbesar dibandingkan dengan variabel lainnya dan terdapat dua variabel yaitu variabel kemampuan petugas dan sosial ekonomi ibu hamil ternyata tidak ada hubungan dengan pelaksanaan manajemen laktasi, maka semua variabel tersebut tidak dimasukkan kedalam analisis regressi logistik hanya lima variabel yang menunjukan adanya hubungan.

\section{d. Analisis multivariat terhadap pelaksanaan mananjemen Laktasi.}

Pada tahap ini dilakukan analisis secara simultan terhadap semua variabel yang termasuk determinan, terhadap pelaksanaan manajemen laktasi pada ibu hamil trimester II dan III, dengan menggunakan uji regressi logistik berganda dengan metode "Enter". Metode ini dipilih oleh karena output nya menggambarkan semua kontribusi variabel terhadap variabel akibatnya, sehingga dapat dibuat model matematik dari persamaan regressinya, yang disajikan sebagai berikut :

Tabel.15. Hasil uji multivariat faktor determinan terhadap pelaksanaan manajemen laktasi pada ibu hamil diwilayah kerja Puskesmas Kalumata Kecamatan Ternate Selatan Kota Ternate Propinsi Maluku Utara. tahun 2013

\begin{tabular}{lccccccc}
\hline & & & & & & \multicolumn{2}{c}{ OR dgn C.I 95\% } \\
\cline { 7 - 9 } \multicolumn{1}{c}{ VARIABEL } & $\mathrm{B}$ & Wald & DF & P & OR & BB & BA \\
\hline Pengetahuan ibu hamil & 2.353 & 21.178 & 1 & 0.000 & 10.519 & 3.861 & 28.658 \\
\hline Kepatuhan ibu hamil & 1.926 & 6.661 & 1 & 0.010 & 6.862 & 1.589 & 29.623 \\
\hline Dukungan suami & 1.292 & 7.159 & 1 & 0.007 & 3.640 & 1.413 & 9.377 \\
\hline Pelayanan kesehatan & 1.730 & 14.431 & 1 & 0.000 & 5.639 & 2.310 & 13.764 \\
\hline Kemampuan petugas kes & 1.251 & 7.174 & 1 & 0.007 & 3.494 & 1.399 & 8.729 \\
\hline Sosial budaya & 0.311 & 0.394 & 1 & 0.530 & 1.365 & 0.516 & 3.160 \\
\hline Constant & -6.184 & 34.808 & 1 & 0.000 & 0.002 & & \\
\hline
\end{tabular}

Sumber : Data primer.

Tabel 15 menunjukkan variabel yang termasuk faktor determinan, yang diduga mempengaruhi pelaksanaan manajemen laktasi pada ibu hamil trimester II dan III diwilayah kerja Puskesmas Kalumata

\section{PEMBAHASAN}

Penelitian ini memfokuskan diri pada penilaian hubungan antara faktor determinan (Pengetahuan, Kepatuhan, Dukungan Suami, Pelayanan Kesehatan, Kemampuan Petugas, Status ekonomi, serta Budaya Lokal),
a. Hubungan antara Pengetahuan Ibu Hamil dengan pelaksanaan Manajemen Laktasi.

Berdasarkan hasil analisis menerangkan bahwa dari total responden (180) terdapat tt 121 (67.2\%) yang memiliki pengetahuan baik dan 59 (32.8\%) memiliki pengetahuan kurang . Dari jumlah ibu hamil yang memiliki pengetahuan baik tidak semua mempunyai manajemen laktasi baik hanya $(63.6 \%)$ yang memiliki manajemen laktasi baik. Hasil uji statistik bivariat maupun multivariate menunjukkan adanya hubungan secara kosisten yakni $(\mathrm{p}=0.000)$ dengan besar kontribusi $(\mathrm{Phi})=28.0 \%$. Besarnya resiko yang ditimbulkan oleh tingkat pengetahuan ibu hamil yang kurang dinilai dengan menggunakan regresi logistic berganda memperlihatkan nilai OR $\{\operatorname{Exp}(B)\}=10.519$ kali dibandingkan dengan tingkat pengetahuan baik dalam pelaksanaan manajemen laktasi 
b. Analisis hubungan antara kepatuhan ibu hamil dengan pelaksanaan manajemen laktasi.

Hasil analisis menunjukan dari total responden (180) terdapat 124 (68.9\%) yang mendapat pelayanan yang sesuai standar dan yang kurang mendapat pelayanan sesuai standar 56 (31.1\%). Dari jumlah ibu hamil yang mendapat pelayanan sesuai standar hanya terdapat ( $60.5 \%)$ yang memiliki manajemen laktasi baik.

Hasil uji statistik bivariat menunjukkan adanya hubungan secara kosisten yakni ( $\mathrm{p}=$ 0.000) namun uji multivariate didapatkan hasil yang berbeda yakni $(\mathrm{p}=0.010)$ dengan besar kontribusi $(\mathrm{Phi})=33.4 \%$. Besarnya resiko yang ditimbulkan oleh tingkat kepatuhan ibu yang kurang dinilai dengan menggunakan regresi logistic berganda memperlihatkan nilai dengan besar resiko tingkat kepatuhan yang kurang atau OR $\{\operatorname{Exp}(\mathrm{B})\}=6.862$ kali dibandingkan dengan tingkat kepatuhan baik dalam pelaksanaan manajemen laktasi.

c. Analisis Hubungan Dukungan Suami Dengan Pelaksanaan Manajemen Laktasi

Berdasarkan hasil analisis hubungan dukungan suami dengan pelaksanaan manajemen laktasi memperlihatkan bahwa dari total responden (180) terdapat 119 (66.1\%) yang mendapat dukungan suami dan yang kurang mendapat dukungan suami adalah sebanyak 61 (33.9\%). Dari jumlah ibu hamil yang mendapat dukungan suami hanya terdapat $(61.3 \%)$ yang memiliki manajemen laktasi baik.

d. Analisis Hubungan Pelayanan Kesehatan Dengan Pelaksanaan Manajemen Laktasi.

Hasil analisis antara hubungan pelayanan kesehatan dengan pelaksanaan manajemen laktasi memperlihatkan bahwa dari total responden (180) terdapat 124 (68.9\%) yang mendapat pelayanan yang sesuai standar dan yang kurang mendapat pelayanan sesuai standar 56 (31.1\%). Dari jumlah ibu hamil yang mendapat pelayanan sesuai standar terdapat ( $60.5 \%)$ yang memiliki manajemen laktasi baik.

e. Analisis Hubungan Antara kemampuan Petugas Dengan Pelaksanaan Manajemen Laktasi. $\begin{array}{cccr}\text { Hasil } & \text { Analisis } & \text { antara } & \text { hubungan } \\ \text { kemampuan } & \text { petugas kesehatan } & \text { dengan } \\ \text { pelaksanaan } & \text { manajemen } & \text { laktasi }\end{array}$ memperlihatkan bahwa dari dari total responden (180) terdapat $116(64.4 \%)$ yang menyatakan kemampuan petugas baik dan yang menyatakan kemampuan petugas kurang $64(35.6 \%)$.

Dari jumlah ibu yang menyatakan kemampuan petugas kesehatan dalam pelayanan ANC baik hanya terdapat (59.5\%) yang memiliki manajemen laktasi baik. Hasil uji statistik bivariat menunjukkan adanya hubungan secara kosisten yakni $(\mathrm{p}=0.043)$ namun uji multivariate didapatkan hasil yang berbeda yakni $(\mathrm{p}=0.007)$ dengan besar kontribusi $(\mathrm{Phi})=15.1 \%$. nBesarnya resiko yang ditimbulkan oleh tingkat kemampuan petugas yang kurang dinilai dengan menggunakan regresi logistic berganda memperlihatkan nilai OR $\{\operatorname{Exp}(B)\}=3.494$ kali dibandingka dengan tingkat kemampuan petugas baik dalam pelaksanaan manajemen laktasi.

f. Analisis Hubungan Antara Sosial Ekonomi Dengan Pelaksanaan Manajemen Laktasi.

pelaksanaan manajemen laktasi memperlihatkan bahwa dari total responden (180) terdapat 131 (72.8\%) yang mempunyai sosial ekonomi baik dan yang kurang adalah $49(27.2 \%)$. Dari jumlah ibu hamil yang sosial ekonomi baik hanya terdapat 67 orang (51.1\%) yang memiliki manajemen laktasi baik.

Hasil uji statistik Chi-square menunjukkan hasil yang tidak bermakna $(p=0.227)$, ini berarti tidak terdapat hubungan antara status ekonomi dengan manajemen laktasi yang baik.

g. Analisis Hubungan Antara Sosial Budaya Dengan Pelaksanaan Manajemen Laktasi.

Berdasarkan hasil analisis hubungan antara soial budaya dengan pelaksanaan manajemen laktasi memperlihatkan bahwa dari total responden (180) terdapat 129 (71.7\%) yang mempunyai sosial budaya baik dan yang kurang adalah 51 (28.3\%). sedangkan dari 129 ibu dengan budaya lokal yang baik terdapat 76 (58.9\%)ibu yang memiliki manajemen laktasi yang baik. Hasil uji statistic bivariat menunjukkan adanya hubungan secara kosisten yakni ( $\mathrm{p}=$ 0.005) lebih kecil dari $(\alpha=0.5)$ namun uji multivariate didapatkan hasil yang berbeda yakni 
$(\mathrm{p}=0.530)$ dengan besar kontribusi $(\mathrm{Phi})=21.0 \%$.

I.

\section{KESIMPULAN DAN SARAN Kesimpulan}

Dari hasil analisis data penelitian yang telah dilakukan pada akhirnya ditarik kesimpulan sebagai berikut :

1. Ada hubungan antara pengetahuan ibu hamil (mengenai ASI) dengan pelaksanaan manajemen laktasi ( $\mathrm{p}=$ 0.000), Artinya semakin baik pengetahuan ibu hamil tentang manajemen laktasi maka semakin tinggi komitmen untuk melakukan apa yang diketahuinya .

2. Ada hubungan antara kepatuhan ibu dengan pelaksanaan manajemen laktasi ( $\mathrm{p}$ $=0.000)$, artinya dengan kepatuhan ibu dalam melaksanakan perawatan pada kehamilan (ANC) maka akan semakin banyak pengetahuan dan pengalaman terutama perawatan payudara guna menunjang keberhasilan masa menyusui.

3. Ada hubungan antara dukungan suami dengan pelaksanaan manajemen laktasi ( $\mathrm{p}$ $=0.005$ ), artinya dengan mendapatkan support atau dukungan baik secara moril maupun materil dari suami maka ibu akan lebih percaya diri Ada hubungan antara kemampuan petugas dengan pelaksanaan manajemen laktasi $(\mathrm{p}=0.043)$ yang berarti dalam memberi palayanan pada ibu hamil dibutuhkan kemampuan petugas terutama kemampuan untuk memberi konseling tentang manajemen laktasi Tidak ada hubungan antara sosial ekonomi dengan pelaksanaan manjemen laktasi $(\mathrm{p}=$ 0.227 ) artinya bahwa status ekonomi tidak menjadi penghambat dalam pelaksanaan manajemen laktasi terutama melakukan perawatan payudara selama masa kehamilan.

4. Ada hubungan antara sosial budaya dengan pelaksanaan manajemen laktasi ( $\mathrm{p}$ $=0.005)$ Artinya masih terdapat kepercayaan dan kebiasaan dalam masyarakat setempat yang kurang mendukung keberhasilan pelaksanaan manajemen laktasi.

\section{Saran}

1. Untuk meningkatkan pengetahuan, perlu dilakukan konseling laktasi secara intensif oleh bidan yang bertugas di desa /kelurahan serta penyuluhan secara teratur setiap trimester kehamilan.

2. Tingkat kepatuhan ibu yang telah ditunjukan dengan hasil yang baik agar dapat dipertahankan dengan meningkatkan penyuluhan dan nasihat setiuap kali ibu melakukan kunjungan ANC.

3. Perlu adanya pelatihan tenaga konselor ASI bagi bidan dan tenaga gizi puskesmas untuk meningkatkan kemampuan mereka dalam memberi konseling tentang manajemen laktasi.

4. Perlu adanya penyuluhan oleh tenaga kesehatan untuk merobah kepercayaan masyarakat tentang budaya yang merugikan dalam proses pemberian ASI.

\section{DAFTARPUSTAKA}

2010. Pemantauan Wilayah setempat ( PWS KIA ). Kemenkes. Jakarta.

2011.Petunjuk Teknis Jaminan Persalinan. Kemenkes, Jakarta.

Adamson C.Paul,at al.2012. Are marginalized women Being left behind? A Population- based study of institutional deliveries in

Karnataka, india diakses dari http://www.biomedcentral.com/1472458/12/30.

Agumbiade and Ogunleye at all 2012 Contraintst to exlusive breastfeeding practice among breastfeeding mother in southwest Nigeria : implications for scaling up.http//www. Internasionalbreastfeedingjournal.com.

Ahmad A, 2011. Perbaikan Gizi Masyarakat di Puskesmas,http//blogspot.com.diakses27 januari 2011 